\title{
In this month's Bulletin
}

In an editorial, Isabelle Nuttall (310) reviews progress towards compliance with the International Health Regulations (2005). Nancy Cox (311) explains why the timing and composition of influenza vaccines varies in tropical regions. Michael Reid \& Fiona Fleck (314-315) report on the 40th anniversary of the Expanded Programme on Immunization. This month the World Health Assembly discusses the post-2015 global tuberculosis strategy and accompanying set of targets. Giovanni Battista Migliori (316-317) tells Fiona Fleck about the contributions made to this work by WHO's Collaborating Centre for Tuberculosis and Lung Diseases at the Fondazione S Maugeri.

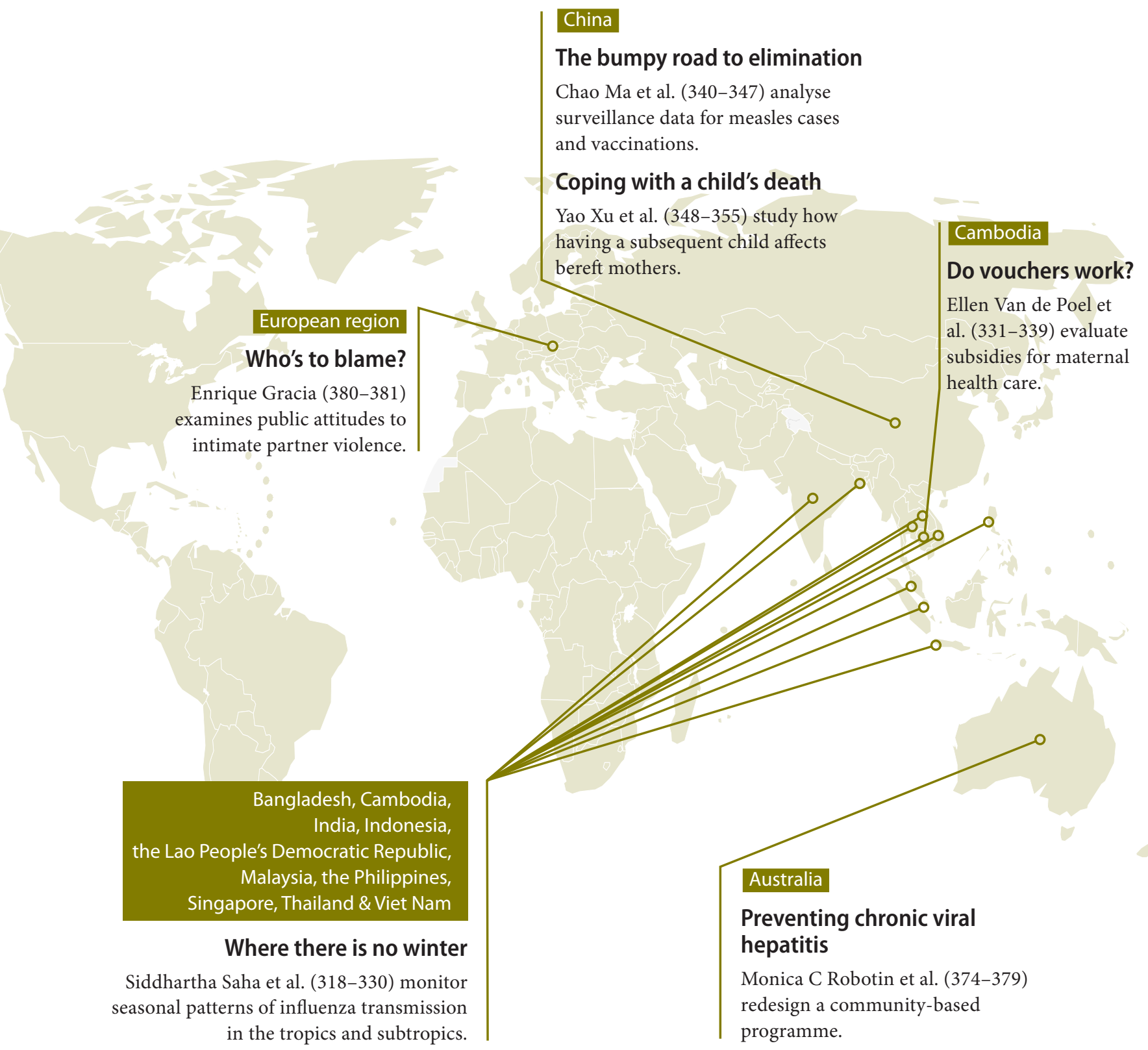

\section{Measuring research gaps}

Shanthi Kappagoda \& John PA Ioannidis (356-366) review research on the prevention and control of neglected tropical diseases.

\section{Updates on hearing impairment}

Bolajoko O Olusanya et al. (367-373)

discuss how to improve care and prevention of hearing loss.

\section{Counting all the costs}

Patrick Lydon et al. (382-384) calculate the health systems cost of delivering routine vaccines. 